\title{
AGE AND THE REHABILITATIVE CARE OF STROKE
}

\author{
CHARLES MURRAY WYLIE, M.D., Dr.P.H.*
}

\author{
University of Michigan School of Public Health, Ann Arbor, Michigan
}

ABSTRACt: Over a nine-year period, 1,223 patients with cerebrovascular accidents were admitted to Montebello State Hospital, a chronic disease institution.

The findings of this study consistently reflect an adverse influence of rising age on the response of CVA patients to rehabilitation. The older patients (over 65) were more disabled on admission, improved less often while in the hospital and died more often than the younger patients. However, the better response of the younger patients did not reduce their length of stay in the hospital (21-23 weeks).

It would be unfair for clinicians to reject for rehabilitation all older patients because of these disadvantages, since our adjustment analysis has shown one way (number of hospital-weeks of care required to obtain a living and improved patient) in which priorities can be balanced for different age groups. It would be premature, however, to apply these figures widely until larger groups of patients are studied in different rehabilitation centers. This can be done quickly if it is agreed that scientific rather than intuitive guidelines for selecting patients deserve urgent atten. tion.

Although we know that older patients with cerebrovascular accidents (CVAs) respond less well to rehabilitative measures than do younger patients (1) , we do not know the magnitude of the difference in response between various age groups. This information is important to the physician who, faced with a shortage of institutional beds, must decide what priority to give to younger applicants for admission. To help with the problem, we shall attempt in this paper to describe systematically the relationship between age and the response to a physical medicine and rehabilitation program in a chronic disease hospital, the Montebello State Hospital in Baltimore.

According to the "rose-colored glasses syndrome," as suggested by Sherwood, no evaluation is needed when our activities are regarded as successful even before they begin (2). Few health workers succumb to this syndrome, but few can eradicate it completely from their major decisions. In the field of geriatrics, we can reduce our dependence on intuition and faith when we have

* Professor, Public Health Administration, University of Michigan School of Public Health, 122 South First Street, Ann Arbor, Michigan 48104.

Formerly Associate Professor, Public Health Administration, Johns Hopkins University School of Hygiene and Public Health, Baltimore, Maryland. 
more scientific information about the subject. On many health problems of the elderly, however, our information is soientifically weak. An outstanding example is the problem of cerebrovascular accidents.

\section{BACKGROUND TO THIS STUDY}

The primary goal of the Montebello State Hospital is the rehabilitation of long-term patients. Administered by the Maryland State Health Department, this chronic disease hospital served as the sole in-patient rehabilitation facility for the Baltimore metropolitan area during 1956 through 1964, the nine-year period of this study.

At the time the application forms for admission were received, the patients were in the midst of or had gone through the acute phase of the CVA. Many had delayed their applications until socio-economic and medical factors had forced them to seek additional help (3). Proportionately fewer applications came from the nonwhite population in the Baltimore area, for reasons that are not clear. During the nine years of this study, applications came from 2,269 CVA patients of all income groups.

\section{PROMPTNESS OF APPLYING}

The period between onset of the CVA and applying for admission ranged from a few days to more than a year, the average delay being forty weeks.

Table 1 shows the relationship between age, sex, race and the time lapse before applying. Among white patients, those between 55 and 74 years were slower to apply than were the younger and older groups. Among nonwhites, however, there was an erratic pattern of applying in relation to age. From the viewpoint that early applicants respond best to rehabilitation, the older white patients in this study were at least as suitable for admission as were the younger groups.

TABLE 1

Average Number of Weeks Between Onset of CVA and Applying for Admission during 1956-1964, by Age, Sex and Race

\begin{tabular}{|c|c|c|c|c|c|c|}
\hline \multirow{2}{*}{ Race \& Sex } & \multirow{2}{*}{\multicolumn{2}{|c|}{ Totals* }} & \multicolumn{4}{|c|}{ Age (yrs.) } \\
\hline & & & under 55 & $55-64$ & $65-74$ & 75 or older \\
\hline White men & $\begin{array}{l}\text { Number } \\
\text { Average Wks. }\end{array}$ & $\begin{array}{l}713 \\
39.5\end{array}$ & $\begin{array}{l}130 \\
36.1\end{array}$ & $\begin{array}{l}209 \\
39.3\end{array}$ & $\begin{array}{l}219 \\
45.3\end{array}$ & $\begin{array}{l}151 \\
34.3\end{array}$ \\
\hline White women & $\begin{array}{l}\text { Number } \\
\text { Average Wks. }\end{array}$ & $\begin{array}{l}761 \\
38.2\end{array}$ & $\begin{array}{l}97 \\
33.8\end{array}$ & $\begin{array}{l}152 \\
47.3\end{array}$ & $\begin{array}{l}292 \\
37.1\end{array}$ & $\begin{array}{l}216 \\
35.4\end{array}$ \\
\hline Nonwhites & $\begin{array}{l}\text { Number } \\
\text { Average Wks. }\end{array}$ & $\begin{array}{l}506 \\
43.0\end{array}$ & $\begin{array}{l}111 \\
34.1\end{array}$ & $\begin{array}{l}178 \\
51.1\end{array}$ & $\begin{array}{l}125 \\
37.6\end{array}$ & $\begin{array}{l}77 \\
50.0\end{array}$ \\
\hline
\end{tabular}

* Includes 23 applicants of unknown age. Excluded are 4 persons of unknown race, and 285 persons for whom the weeks between onset and applying were unknown. 
TABLE 2

Proportion of CVA Applicants with Good Rehabilitation Potential, by Age

\begin{tabular}{l|c|cccc}
\hline & \multicolumn{4}{|c}{ Total* } & \multicolumn{4}{|c}{ Age (yrs.) } \\
\cline { 2 - 6 } & & under 55 & $55-64$ & $65-74$ & 75 or older \\
\hline Applicants & 2,111 & 342 & 580 & 674 & 484 \\
Number with good potential & 560 & 144 & 193 & 160 & 60 \\
Per cent with good potential & $26.5 \%$ & $42.1 \%$ & $33.3 \%$ & $23.7 \%$ & $12.4 \%$ \\
\hline
\end{tabular}

- Excludes 158 applicants who received no classification, usually because of death soon after applying or because the application was withdrawn. Includes 31 applicants of unknown age.

TABLE 3

Age, Sex and Race Distribution of 1,2es CVA Patienls Admilted to Chronic Disease Hospital

\begin{tabular}{l|c|cccc}
\hline \multirow{2}{*}{ Race \& Sex } & Totai* & \multicolumn{4}{|c}{ Per Cent in Age Group } \\
\cline { 2 - 5 } & & under 55 & $55-64$ & $65-74$ & 75 or older \\
\hline White men & 439 & 21.7 & 31.5 & 30.6 & 16.2 \\
White women & 492 & 14.7 & 22.1 & 39.7 & 28.5 \\
Nonwhite men & 152 & 23.9 & 45.0 & 22.5 & 8.6 \\
Nonwhite women & 140 & 28.1 & 34.5 & 25.2 & 12.2 \\
\hline
\end{tabular}

- Includes 6 patients of unknown age. The average for all groups combined was 63.8 years; 63.3 years for WM; 66.3 years for WF; 60.3 years for NWM; and 60.8 years for NWF.

\section{MEDICAL ASSESSMENT OF REHABILITATION POTENTIAL}

Physicians in the community filled out the application forms which gave the medical information about their patients. The hospital staff used this information to classify patients according to their likelihood of responding to rehabilitation. Past experience guided the hospital staff in making these judgments, which were based on such information as the severity of disability, length of illness, blood pressure and electrocardiograph readings, as well as age itself.

Of the 2,111 patients who were classified on application, 27 per cent were judged to have a good rehabilitation potential (Table 2). This proportion fell steadily with increasing age, ranging from 42 per cent of those under 55 years to 12 per cent of those aged 75 years or older.

\section{PATIENTS ADMITTED}

The Montebello State Hospital also admits patients of doubtful potential for a trial period, as well as a few severely ill patients for terminal care. A total of 1,223 CVA patients were admitted during the nine years. Table 3 shows the distribution by age, sex and race. White patients were more numerous and older than nonwhites. Not revealed in the table is the fact that, within 
TABLE 4

Average Disability Score* of Admilted Patients, by Age, Sex and Race

\begin{tabular}{l|cc|c|cc}
\hline & \multicolumn{3}{|c|}{ Men } & \multicolumn{2}{c}{ Women } \\
\cline { 2 - 5 } & under 65 & 65 or odder & under 65 & 65 or older \\
\hline & \multicolumn{3}{|c|}{ Whites } \\
Number admitted & 214 & 172 & 161 & 243 \\
Average score & 53.4 & 35.5 & 46.7 & 34.4 \\
Number admitted & 89 & 36 & Nonwhites & \\
Average score & 50.1 & 32.4 & 42.0 & 33 \\
\hline
\end{tabular}

- The average score for all admissions was 42.5. This table excludes 198 persons for whom no score was obtained, and 5 additional persons of unknown age.

each sex-race group, the average age of the admitted patients was less than the average age of the applicants. The age of all patients admitted averaged 64 years, compared with 66 years for all applicants.

Previous papers have described a reasonably effective disability index, based on eleven activities of daily living $(4,5)$. This index gives a score of 100 points to the patient able to perform all activities skillfully and without help, no points (a score of 0 ) to the patient unable to perform any of the eleven activities, and intermediate scores to patients in between these extremes. The more seriously disabled the patient, the lower his score.

The average score on admission for all patients in this study was 43 points. Table 4 shows the average scores for different sex-race groups; within each group, patients aged 65 years or older had lower scores, indicating more serious disability than in younger patients. The nonwhites tended to have about the same scores as the whites.

Table 5 shows a comparison of the average scores for whites, grouped by varying periods between onset of the CVA and admission to the hospital. Again, the older patients were more disabled. In both age groups, patients admitted early were more seriously disabled than were patients admitted late.

TABLE 5

Average Disability Score of While Patients Admitted, by Weeks between Onset of CVA and Admission, and by Age*

\begin{tabular}{c|c|cc}
\hline $\begin{array}{c}\text { Weeks between } \\
\text { Adnission to Hospital }\end{array}$ & \multicolumn{3}{|c}{ Disability Score } \\
\hline $0-8$ & Total & For Patients under 65 & For Patients 65 or older \\
\hline $9-26$ & 38.7 & 46.4 & 33.1 \\
27 or more & 41.1 & 51.1 & 33.1 \\
& 50.4 & 57.2 & 41.6 \\
\hline
\end{tabular}

"Excludes 118 white patients whose disability score was not determined on admission and an additional 34 patients for whom the weeks between onset of CVA and admission were unknown. 
TABLE 6

Discharge Status of White CVA Patients, by Age and Sex*

\begin{tabular}{l|rr|rc}
\hline & \multicolumn{2}{|c|}{ Men } & \multicolumn{2}{c}{ Women } \\
\cline { 2 - 5 } & under 65 & 65 or older & under 65 & 65 or older \\
\hline Number discharged & 226 & 193 & 173 & 299 \\
Alive, improved & $67.7 \%$ & $49.2 \%$ & $63.6 \%$ & $40.5 \%$ \\
Alive, unimproved & $14.2 \%$ & $17.1 \%$ & $18.5 \%$ & $17.4 \%$ \\
Alive, change unknown & $3.1 \%$ & $2.6 \%$ & $1.7 \%$ & $4.3 \%$ \\
Dead & $15.0 \%$ & $31.1 \%$ & $16.2 \%$ & $37.8 \%$ \\
\hline
\end{tabular}

* Forty white patients were still in the hospital when this study ended.

\section{CLINICAL RESPONSE TO CARE}

Table 6 shows the physician's impression of the status on discharge of the white patients. This impression was based on the physician's memory and clinical notes, and not on the scoring procedure. For each sex, more than twice as many deaths occurred among the older patients. Of those discharged alive, the discharging physician regarded fewer older patients as improved. Ueing the criterion of clinical judgment, therefore, the older patients were less responsive to rehabilitative care.

\section{LENGTH OF HOSPITAL STAY}

Patients discharged by June 30, 1965 had an average stay of twenty-one weeks. Since most deaths occurred soon after admission, the patients alive at the time of discharge had stayed an average of twenty-three weeks. If younger patients respond more rapidly to rehabilitation, they should be expected to leave more promptly. To test this possibility, the average stay for each age group was subdivided according to the promptness of admission, as shown in Table 7. Surprisingly, younger patients tended to stay about the same length of time as the older living discharged patients. It is apparent, therefore, that the better response of younger patients to rehabilitation did not reduce their length of stay in the hospital.

TABLE 7

Average Weeks of Hospital Stay for White Patients Discharged Alive, by Weeks between Onset of CVA and Admission, and by Age*

\begin{tabular}{c|cc}
\hline \multirow{2}{*}{\begin{tabular}{c|c} 
Weeks between Onset of CVA and Adraission \\
to Hospital
\end{tabular}} & \multicolumn{2}{|c}{ Average Stay } \\
\cline { 2 - 3 } & Patients under 65 & Patients 65 or older \\
\hline $0-8$ & 21.2 & 20.3 \\
$9-26$ & 22.4 & 22.0 \\
27 or more & 22.8 & 22.7 \\
\hline
\end{tabular}

- Eight hundred and eighty-eeven white patients had been discharged when this study ended. This table omits 47 of these patients for whom the weeks between onset of CVA and admission were unknown. 
TABLE 8

Response to Hospital Care of White CVA Patients, by Age and Disability Score on Admission

\begin{tabular}{|c|c|c|c|c|}
\hline \multirow{2}{*}{\multicolumn{2}{|c|}{ Admission Score \& Age }} & \multirow{3}{*}{$\begin{array}{c}\begin{array}{c}\text { No. of Patients } \\
\text { Discharged }\end{array} \\
390^{*} \\
479^{*}\end{array}$} & \multicolumn{2}{|c|}{ Per Cent of Patients Discharged } \\
\hline & & & \multirow{2}{*}{$\begin{array}{l}\text { Alive } \\
84.1 \\
63.9\end{array}$} & \multirow{2}{*}{$\begin{array}{r}\text { Improved } \\
67.4 \\
44.9\end{array}$} \\
\hline All scores & $\begin{array}{l}\text { Age: } \\
\text { Under } 65 \\
65+\end{array}$ & & & \\
\hline $0-15$ & $\begin{array}{c}\text { Under } 65 \\
65+\end{array}$ & $\begin{array}{l}44 \\
94\end{array}$ & $\begin{array}{l}72.7 \\
58.5\end{array}$ & $\begin{array}{l}52.3 \\
27.7\end{array}$ \\
\hline $20-35$ & $\begin{array}{c}\text { Under } 65 \\
65+\end{array}$ & $\begin{array}{r}69 \\
131\end{array}$ & $\begin{array}{l}82.6 \\
71.8\end{array}$ & $\begin{array}{l}68.1 \\
57.3\end{array}$ \\
\hline $40-55$ & $\begin{array}{c}\text { Under } 65 \\
65+\end{array}$ & $\begin{array}{r}114 \\
95\end{array}$ & $\begin{array}{l}91.2 \\
82.1\end{array}$ & $\begin{array}{l}79.8 \\
68.4\end{array}$ \\
\hline $60-100$ & $\begin{array}{c}\text { Under } 65 \\
65+\end{array}$ & $\begin{array}{r}127 \\
64\end{array}$ & $\begin{array}{l}96.1 \\
90.6\end{array}$ & $\begin{array}{l}78.7 \\
73.4\end{array}$ \\
\hline
\end{tabular}

* Includes 131 with unknown admission score.

\section{IMPROVEMENT WITH EQUAL DIBABILITY}

The older patients were more disabled on admission (Table 4). In Table 8, adjustment is made for this difference by comparing the outcome of care for older and younger white patients who had the same range of disability on admission.

In each disability group, fewer older patients than younger patients were discharged alive and improved. However, older patients with mild disability on admission often responded better than younger patients with more serious disability. By selecting for admission the less seriously disabled, one can obtain a group of older patients who respond reasonably well to rehabilitation.

\section{SYSTEMATIC ASSESSMENT OF THE EFFECT OF AGE}

On many occasions, however, the choice between patients for admission will need more sophisticated guidelines. How can clinicians balance the effect of age against other factors? The method of cost-benefit analysis may offer a rational way to answer this question.

The ideal analysis should give a dollar value to the cost of the rehabilitation effort. This cost would then be expressed in terms of the resulting benefit - a measurable and desirable end-result such as improvement of the patient by the time of discharge. Care of the unimproved and dead patients would have to be included as part of the cost of producing the improved patients. This process will have to continue until the time comes when clinicians can admit only those patients who will be discharged alive and improved; even decades from now, such skill in prognosis may well be impossible. 
TABLE 9

Average Hospital Weeks of Care Needed to Discharge a Living and Improved White Patient, by Disability Score on Admission, and by Age*

\begin{tabular}{|c|c|c|c|c|c|c|}
\hline \multirow[b]{2}{*}{ Admisuion Score } & \multirow[b]{2}{*}{ Age } & \multirow{2}{*}{$\begin{array}{c}\text { Total Weeks } \\
\text { in Hospital for } \\
\text { all Patients }\end{array}$} & \multicolumn{2}{|c|}{$\begin{array}{c}\text { Number of Patients } \\
\text { Discharged }\end{array}$} & \multicolumn{2}{|c|}{$\begin{array}{l}\text { Average Hospital } \\
\text { Weeks per }\end{array}$} \\
\hline & & & $\begin{array}{l}\text { Alive } \\
\text { b. }\end{array}$ & $\begin{array}{l}\text { Improved } \\
\text { c. }\end{array}$ & $\begin{array}{c}\text { Living } \\
\text { discharged } \\
\text { patient } \\
\frac{\mathbf{a}}{\vec{b}}\end{array}$ & $\begin{array}{c}\text { Improved } \\
\text { discharged } \\
\text { patient } \\
\frac{\mathbf{a}}{\mathrm{c}}\end{array}$ \\
\hline \multirow[t]{2}{*}{$0-15$} & Under 65 & 1352 & 32 & 23 & 42.3 & 58.8 \\
\hline & $65+$ & 1862 & 65 & 26 & 39.9 & 71.6 \\
\hline \multirow{2}{*}{$20-35$} & Under 65 & 2157 & 57 & 47 & 37.8 & 46.9 \\
\hline & $65+$ & 3270 & 94 & 75 & 34.8 & 43.6 \\
\hline \multirow[t]{2}{*}{$40-55$} & Under 65 & 2438 & 104 & 91 & 23.4 & 26.8 \\
\hline & $65+$ & 2471 & 78 & 65 & 31.7 & 38.0 \\
\hline \multirow[t]{2}{*}{$60-100$} & Under 65 & 2367 & 122 & 100 & 19.4 & 23.7 \\
\hline & $65+$ & 1503 & 58 & 47 & 25.9 & 32.0 \\
\hline
\end{tabular}

* This table omits figures for 131 discharged patients for whom the admission score was unknown.

This study has not yet reached the stage where we can assign dollar values to the rehabilitation effort. However, a less precise measure of "cost" is the hospital-week of care for one patient. Although the dollar value for a week of care will vary between individuals, it varies less when averaged for groups. This forms the rationale for the figures in Table 9.

It took an average of 31 hospital-weeks of care to produce a living discharged patient; this could be selected as one measurable and desired result. It took 40 hospital-weeks to produce an improved discharged patient,- -who was thus less common than the living discharged patient. Table 9 shows that, in three of the four disability groups, more hospital-weeks were needed to improve the older patients. Moreover, as the disability became less serious, it required fewer weeks to produce an improved discharged patient in each age group.

Several factors limit the usefulness of Table 9. One is the small number of patients on which the figures are based. Another is that different institutions select patients differently, receive different types of applicants, and provide rehabilitative care of varying intensity; the number of weeks of care will, therefore, vary between different institutions. A third limiting factor is that the "improved patient" can range from one who has improved slightly to one who has improved a great deal. However, Table 9 indicates one way in which priorities can be balanced for different age groups.

\section{(For Summary, see Abstract at beginning of article.)}

\section{REFERENCES}

1. Wylie, C. M.: Age and long-term hospital care following cerebrovascular accidents, J. Am. Geriatrics Soc. $12: 763$ (Aug.) 1864.

2. Sherwood, C. C.: Issues in measuring results of action programs, Welfare in Review 5 : 13 (Aug.-Sept.) 1967. 
3. Wylie, C. M.: Factors influencing CVA patients to seek rehabilitative care, Public Health Rep. 79: 525 (June) 1964.

4. Wylie, C. M., and White, B. K.: A measure of disability, Arch. Environ. Health 8: 834 (June) 1964.

5. Wylie, C. M.: Gauging the response of stroke patients to rehabilitation, J, Am. Geriatrics Soc. 15: 797 (Sept.) 1967. 